\title{
THE PECULIARITIES OF THE BODY'S EXTERNAL STRUCTURE AND INDICATORS OF CENTRAL HEMODYNAMICS OF VOLLEYBALL PLAYERS OF DIFFERENT POSITIONS
}

DOI: 10.36740/WLek202005115

\author{
Larisa A. Sarafinjuk', Olga P. Khapitska', Larysa Ya. Fedoniuk'2, Lyudmila V. Fomina' ${ }^{1}$ Daria A. Merkulova', \\ Yuriy V. Kyrychenko ${ }^{1}$, Petro V. Sarafinjuk ${ }^{3}$ \\ 'NATIONAL PIROGOV MEMORIAL MEDICAL UNIVERSITY, VINNYTSIA, UKRAINE \\ 2. HORBACHEVSKY TERNOPIL NATIONAL MEDICAL UNIVERSITY, TERNOPIL, UKRAINE \\ ${ }^{3}$ VINNYTSIA MYKHAILO KOTSYUBYNSKYI STATE PEDAGOGICAL UNIVERSITY, VINNYTSIA, UKRAINE
}

\begin{abstract}
The aim was to determine the main differences in the external structure of the body and the of central hemodynamics parameters in of high-level sports skills volleyball players of the juvenile age with the role of libero, hitters and setters.

Materials and methods: 116 volleyball players of high level athletic skill of the youth age from 16 to 20 years old. The control group included 140 practically healthy girls who were not engaged in sports of the corresponding age. Anthropometric investigation was performed according to Bunak's V.V. and Martirosov's E.G. method, rheographic according to the method of Ronkin M.A. and Ivanov L.B. The reliability of the difference between independent quantitative values was determined using Mann-Whitney U-test. Results: It was established that volleyball players have significantly higher total, longitudinal, circumferential dimensions of the body, width of distal epiphyses, transverse diameters of the chest and pelvis in comparison with girls, who are not involved in sport. According to the most parameters of the body external structure the hitters are predominate than setters and libero. In hitters and setters, most anthropo-somatotypological parameters are larger than in nonathletes. The stroke and minute volumes, the impact index, the volume velocity of the blood and the capacity of the left ventricle in volleyball players are significantly higher. Specific peripheral resistance is significantly lower than that of girls who are not involved in sports. Between the volleyball players of different positions in the value of the central hemodynamics parameters, there were no significant differences, except for the impact index, which is significantly higher in libero than in the hitters.

Conclusions: The external structure of the body, anthropometric parameters and indicators of central hemodynamics depend of volleyball player's position and have some peculiarities.
\end{abstract}

KEY WORDS: volleyball, sport position, athletes, anthropometric parameters, rheography, central hemodynamics

Wiad Lek. 2020;73(5):920-924

\section{INTRODUCTION}

Scientific research confirms that for professional sports selection it is necessary to take into account the morphofunctional peculiarities of athletes' body $[1,2,3]$. In many cases, the limiting factor for the achievement of high sports results is the discrepancy between personal anthropo-somatotypological parameters and need of a particular sport $[4,5]$. The problem of the optimal functional state of the cardiovascular system in athletes is determined by the short-term tasks of preparation for a specific sport event, as well as its long-term status, which ensures high achievements of sports for a long period of time. The leading limiting chain in the degree of physical fitness of an athlete is the state of the cardiovascular system $[6,7,8]$. The functional state of the central hemodynamics enables the most rapid detection of signs of overwork and overtraining. The peculiarities of the human body structure of the athletes influence the manning of the team, the choice of the tactical drawing of the game in defense and attack, on the definition of training techniques $[9,10]$. Until recently, the morphological and functional parameters of the athletes' body of sports games were evaluated on average values of parameters: football players, handball players, basketball players. Recently, there has been a tendency to develop an evaluation of these parameters among athletes depending on the position of the game (goalkeeper, defender, half-back, forward) in the specific sport games $[11,12,13]$. The sport position determines the athlete's actions on the sportsground, proposes certain requirements for his morphofunctional parameters and the special orientation of the training process. Therefore, it is important to establish the features of central hemodynamics, total and partial body parameters, component composition of the body mass and somatotypological characteristics in predicting the possibilities of volleyball players in different positions.

\section{THE AIM}

The aim was to define the main differences in the external structure of the body and in parameters of central hemodynamics in volleyball players of the youth of the high level of sports skill with the position of libero, hitters and setters. 
Table I. Differences of total body dimensions in girls, depending on sports activities

\begin{tabular}{|c|c|c|c|c|c|}
\hline Parameters & Group & $\mathbf{M} \pm \sigma$ & $\mathbf{p}_{1}$ & $\mathbf{p}_{2}$ & $\mathbf{p}_{3}$ \\
\hline \multirow{4}{*}{ Body weight (kg) } & Hitters & $66.55 \pm 8.17$ & & $<0.001$ & $<0.05$ \\
\hline & Setters & $59.69 \pm 7.04$ & $<0.001$ & & $>0.05$ \\
\hline & Libero & $59.54 \pm 10.01$ & $<0.05$ & $>0, .05$ & \\
\hline & Control & $55.74 \pm 7.28$ & $<0.001$ & $<0.05$ & $>0.05$ \\
\hline \multirow{4}{*}{ Body length $(\mathrm{cm})$} & Hitters & $175.9 \pm 5.7$ & & $<0.001$ & $<0.01$ \\
\hline & Setters & $169.0 \pm 5.0$ & $<0.001$ & & $>0.05$ \\
\hline & Libero & $167.7 \pm 6.5$ & $<0.01$ & $>0.05$ & \\
\hline & Control & $164.1 \pm 6.8$ & $<0.001$ & $<0.001$ & $>0.05$ \\
\hline \multirow{4}{*}{ Area of the body surface $\left(\mathrm{m}^{2}\right)$} & Hitters & $1.81 \pm 0.12$ & & $<0.001$ & $<0.05$ \\
\hline & Setters & $1.68 \pm 0.10$ & $<0.001$ & & $>0.05$ \\
\hline & Libero & $1.67 \pm 0.15$ & $<0.05$ & $>0.05$ & \\
\hline & Control & $1.59 \pm 0.12$ & $<0.001$ & $<0.01$ & $>0.05$ \\
\hline
\end{tabular}

Notes: $p_{1}$ - an indicator of statistical significance of differences in anthropometric parameters by hitters with other groups; $p_{2}-$ an indicator of statistical significance of differences in anthropometric parameters by setters with other groups; $p_{3}$ - an indicator of statistical significance of differences in anthropometric parameters by libero with other groups.

Table II. Differences in the partial dimensions of the body in girls depending on sports activities

\begin{tabular}{|c|c|c|c|c|c|}
\hline Parameters & Group & $\mathbf{M} \pm \sigma$ & $p_{1}$ & $\mathbf{p}_{2}$ & $\mathbf{p}_{3}$ \\
\hline \multirow{4}{*}{ Length of the arm } & Hitters & $78.12 \pm 4.31$ & & $<0.001$ & $>0.05$ \\
\hline & Setters & $75.79 \pm 3.02$ & $<0.001$ & & $>0.05$ \\
\hline & Libero & $77.58 \pm 6.18$ & $>0.05$ & $>0.05$ & \\
\hline & Control & $73.06 \pm 0.38$ & $<0.001$ & $<0.01$ & $<0.05$ \\
\hline \multirow{4}{*}{ Length of the trunk } & Hitters & $53.63 \pm 4.27$ & & $<0.001$ & $<0.05$ \\
\hline & Setters & $50.05 \pm 3.00$ & $<0.001$ & & $>0.05$ \\
\hline & Libero & $50.41 \pm 3.03$ & $<0.05$ & $>0.05$ & \\
\hline & Control & $48.75 \pm 0.27$ & $<0.001$ & $<0.01$ & $<0.058$ \\
\hline \multirow{4}{*}{ Length of the leg } & Hitters & $91.93 \pm 5.43$ & & $<0.001$ & $<0.05$ \\
\hline & Setters & $89.02 \pm 4.32$ & $<0.001$ & & $>0.05$ \\
\hline & Libero & $88.03 \pm 4.69$ & $<0.05$ & $>0.05$ & \\
\hline & Control & $86.27 \pm 0.48$ & $<0.001$ & $<0.05$ & $>0.05$ \\
\hline \multirow{4}{*}{ Girth of the shin in lower third } & Hitters & $23.20 \pm 2.84$ & & $<0.05$ & $<0.05$ \\
\hline & Setters & $22.46 \pm 1.02$ & $<0.05$ & & $>0.05$ \\
\hline & Libero & $21.66 \pm 1.56$ & $<0.05$ & $>0.05$ & \\
\hline & Control & $22.32 \pm 1.56$ & $<0.001$ & $>0.05$ & $>0.05$ \\
\hline \multirow{4}{*}{ Girth of the chest during expiration } & Hitters & $94.20 \pm 6.18$ & & $<0.05$ & $>0.05$ \\
\hline & Setters & $91.88 \pm 5.04$ & $<0.05$ & & $>0.05$ \\
\hline & Libero & $91.67 \pm 5.82$ & $>0.05$ & $>0.05$ & \\
\hline & Control & $86.09 \pm 6.48$ & $<0.001$ & $<0.001$ & $<0.05$ \\
\hline
\end{tabular}

Notes: $p_{1}$ - an indicator of statistical significance of differences in anthropometric parameters by hitters with other groups; $p_{2}-$ an indicator of statistical significance of differences in anthropometric parameters by setters with other groups; $p_{3}-$ an indicator of statistical significance of differences in anthropometric parameters by libero with other groups.

\section{MATERIALS AND METHODS}

On the base of the Scientific-Research Center of the E. Pirogov Vinnitsa National Medical University a comprehensive survey of 116 volleyball players of high level athletic skill (from 16 to 20 years old) was done. Sports experience in all volleyball players is more than 3 years. All athletes at the time of the survey were on the preparatory stage of the training cycle and had a high level of athletic skill. The age distribution among athletes was as follows: 16 -year-olds - 24 persons (20.69\%); 17 years old $-21(18.1 \%) ; 18$ years old $-28(24.14 \%) ; 19$ years 
old - 23 (19.83\%); 20 years old - 20 (17.24\%). According to the sport degree, the distribution among volleyball platers was as follows: 79 persons $(68.11 \%)$ had the first adult rank, 31 candidates $(26.72 \%)$, sports masters - 6 (5.17\%). For the sport's role volleyball players were divided into 3 groups: hitters - 78 (67.24\%), setters - 29 (25\%), libero - 9 (7.76\%). The control group included 140 practically healthy girls who were not engaged in sports of the corresponding age. In the group of young girls who were not engaged in sports, the age distribution was as follows: 16-year-olds - 27 (19.69\%); 17 years old $-32(22.83 \%) ; 18$ years old $-25(18.11 \%) ; 19$ years old - 25 (18.11\%); 20 years old - 31 (21.26\%).

Commission on Bioethics of Vinnitsa National Medical University M.I. Pirogov (report № 7 dated June 8, 2015) established that the studies did not deny the main bioethical norms of the Helsinki Declaration adopted by the General Assembly of the World Medical Association, Council of Europe Convention on Human Rights and Biomedicine, relevant provisions of World Health Organization, International Council of Scientific Medical Societies, International Code of Medical Ethics and the laws of Ukraine and may be used in scientific work. All volleyball players signed a form of informed consent. Participants were provided with anonymity and confidentiality of data.

Anthropometric research was performed according to the Bunak's V.V. (1941) method [14]. Were determined total (body length and weight) and partial dimensions: 5 longitudinal, 15 circumferential, 10 transverse, 2 anterior-posterior, 7 craniometric dimensions and thickness of 8 dermato-extracting creases. According to the Martirosov's E.G. (1982) method [15] were determined: length of the trunk, arm and leg. Rheographic parameters were determined by computer diagnostic complex according to the method of Ronkin M.A. and Ivanov L.B. (1997) [16]. Given the performance EGG, the distance between the electrodes, height and weight and body surface area, arterial pressure, heart rate and using formulas (Vinogradova, 1986) we calculated the parameters of central hemodynamics [17]. The statistical analysis of the results was carried out using the package «STATISTICA 5.5» (license number AXXR910A374605FA). We evaluated the character of the distributions for each of the obtained variation series for Shapiro-Wilc, the mean for each studied feature, the errors of the arithmetic mean and the standard quadratic deviation. Reliability of difference values between independent quantitative variables were determined using the U-Mann-Whitney criterion.

\section{RESULTS}

It is established that among volleyball players the largest weight of the body has hitters in compare with the libero, this parameter in hitters is larger than in libero, setters and in girls of the control group.

Weight of the body in setters is larger than in non-athletes (Table I). A real difference in body length between hitters and nonathletes and volleyball players of two other sports positions was revealed. In setters, the value of this parameter is significantly higher than that of control group girls.
The area of the body surface, as well as the two previous anthropometric dimensions, has statistically significant value in volleyball players, compared with girls, who are not involved in sport.

According to the sport position, it has been established that the hitters have significantly higher values of length, weight and area of the body surface than setters, libero and nonathletes. In libero, in comparison with volleyball players of a different positions, total body parameters are the smallest, but the real difference is established only between them and the hitters. Attention is drawn to the fact that total dimensions do not differ from the libero compared to girls, who are not involved in sport.

It was revealed that in highly skilled athletes all longitudinal body dimensions are significantly higher than in nonathletes $(\mathrm{p}<0.001)$. It is evidenced by the highest anthropometric points. anthropometric dimensions In hitters are significantly higher than that of girls of other groups of comparison. Compared to girls, who are not involved in sports, the setters have a higher altitude of all anthropometric points, with the exception of the trochanterial point, and the libero have only higher altitude of the suprasternal point.

Volleyball players of the general group have a larger length of the arm, length of the trunk and length of the legs than nonathletes, the volleyball players of a separate sport position maintain the established regularity (Table II).

Volleyball players have larger values of the width of the distal shoulder epiphyses $(6.28 \pm 0.41) \mathrm{cm}$, forearm $(5.12 \pm 0.33)$ $\mathrm{cm}$ (in both cases $\mathrm{p}<0.001)$, hip $(8.54 \pm 0.83) \mathrm{cm}$ and shin $(6.64 \pm 0.51) \mathrm{cm}$ (in both cases $\mathrm{p}<0.01)$ than nonathletes. In hitters, in comparison with girls, who are not involved in sport, the transverse dimensions are significantly higher (in all cases, $\mathrm{p}<0.001$ ), in setters only the width of the distal epiphysis of the shoulder $(\mathrm{p}<0.05)$ is significantly greater $(\mathrm{p}<0.05)$. In libero in comparison to the control group there are no real differences. It should be noted that in setters and libero these dimensions practically do not differ, whereas in athletes of these groups the width of the distal epiphysis is substantially less than that of the hitters.

Analyzing changes in body diameters, it was found that volleyball players have transverse middle thoracic $(26.49 \pm 1.83) \mathrm{cm}$ and lower chest $(23.65 \pm 2.19) \mathrm{cm}$ dimensions significantly higher than nonathletes $(\mathrm{p}<0.001)$. The thickness of the chest, which is indicated by the anterio-posterior middle chest dimension $(17.79 \pm 2.55)$ $\mathrm{cm}$, is also greater $(\mathrm{p}<0.01)$. According to the width of the shoulders, group of volleyball players $(36,26 \pm 2,33)$ $\mathrm{cm}$ and group of nonathletes $(35,94 \pm 2,56) \mathrm{cm}$ are significantly not different. Thus, adaptive changes in volleyball players are more prominent in the dimension of the chest. It was established that in volleyball players in comparison with nonathletes, the external conjugate $(19.26 \pm 1.47) \mathrm{cm}$ $(\mathrm{p}<0.001)$, interspinal $(25.46 \pm 1.87) \mathrm{cm}(\mathrm{p}<0.05)$, intercrestal $(29.22 \pm 2.54) \mathrm{cm}(\mathrm{p}<0,001)$ and intertrochanterial $(32.82 \pm 2.15) \mathrm{cm}(\mathrm{p}<0.001)$ dimensions are significantly larger. Interspinal dimension does not have a significant difference between athletes of different positions, intercrestal dimension - significantly higher in the hitters than 
in the setters and the libero, intertrochanterial dimension and external conjugate - in the hitters, compared with the setters. All circumferential body dimensions in the general group of volleyball players are significantly higher than that of girls, who are not involved in sports (mostly $\mathrm{p}<0.001$ ).

In compare of the parameters of systolic, diastolic and average arterial pressure between nonathletes and volleyball players of a high level of athletic skill of the same age, between any comparison group no significant difference was found. Parameters of blood pressure are almost the same level in all volleyball players with different sports positions.

One of the important indicators of central hemodynamics is stroke volume, which at nonathletic persons $(69.15 \pm 20.99)$ $\mathrm{ml}$ significantly lower than in the total group of athletes $(78.76 \pm 15.36) \mathrm{ml}(\mathrm{p}<0.001)$ and volleyball players of different positions: hitters $(78.68 \pm 16.08) \mathrm{ml}(\mathrm{p}<0.001)$, setters (77.04 \pm 15.15$) \mathrm{ml}(\mathrm{p}<0.05)$, libero $(84.71 \pm 8.282) \mathrm{ml}(\mathrm{p}<0.01)$; we have not found significant differences in the value of this parameter between the different volleyball sports specialization, although it should be noted that by libero the average value of this indicator is the highest. We found that volleyball players' minute volume of blood $(4.93 \pm 0.96) 1$ was significantly higher $(\mathrm{p}<0.001)$ than girls who do not play sports $(4.57 \pm 1.39) \mathrm{l}$, this regularity was observed in a case of volleyball special positions: hitters have this parameter $(4.96 \pm 0.99) 1$ significantly larger $(\mathrm{p}<0.01)$, but setters $(4.90 \pm 1.00) 1$ have a tendency to meaning its larger $\mathrm{p}<0.055)$ when to compare them with nonathletic persons. At volleyball players of different parameters, the minute volume is on one level. The size of stroke index $(\mathrm{ml} /$ $\mathrm{m}^{2}$ ) has no significant differences when comparing the overall group, volleyball players and not athletes, but we found out, that by libero this parameter $(51.22 \pm 6.85)$ has the greatest significance in the present sample, significant difference $(p<0,05)$ in the value of the hemodynamic parameter is set by comparing athletes of the position of hitters (43.32 \pm 9.11$)$ and girls who are not involved in sports $(43.11 \pm 12.75)$. The value of cardiac index $\left(1 / \mathrm{m}^{2}\right)$ in the total group of athletes $(2.83 \pm 0.63)$ and volleyball players of different positions has no significant differences when compared with each other and with a group of girls who are not involved in sports $(2.88 \pm 0.83)$.

We found out that the value of the specific peripheral resistance has no significant difference between groups of volleyball players, a total group of sportsmen and not athletes, it should be noted that by libero this parameter is the lowest average value, by hitters - the highest, difference by comparing these groups are unreliable. Total peripheral resistance $\left(\mathrm{Din} / \mathrm{s} / \mathrm{cm}^{5}\right.$ ) by nonathletes $(1620.7 \pm 472.4)$ is significantly greater than in the general group of volleyball players $(1454.7 \pm 299.8)(\mathrm{p}<0.01)$ and hitters $(1454.5 \pm 305.4)(\mathrm{p}<0.05)$. Between volleyball players with different command specialization the changes in the value of this parameter are unreliable, by libero - the lowest value of this parameter (1433.4 \pm 271.5$)$, the setters - the largest (1462.2 \pm 304.0$)$. Girls, who are not involved in sports, significantly concede in size volume speed of blood $(\mathrm{ml} / \mathrm{s})$ than volleyball players', we found significant differences in the value of this parameter between the control group $(254.3 \pm 74.14)$ and the general group of athletes $(288.2 \pm 51.14)$ and a group of hitters

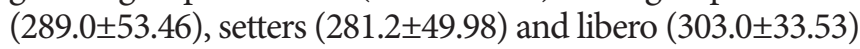

$(\mathrm{p}<0.01-0.001)$. By libero the average value of this parameter is largest in the present sample, but the difference between athletes of different positions is insignificant. Sportswomen, who are engaged in volleyball, have more power of left ventricle $(p<0.05-0.001)$ than girls who do not play sports.

\section{DISCUSSION}

The high level of modern sports achievements requires specific knowledge in the field of morpho-functional features of the organism, which serves as a transitional step to a deeper study of individual sports. There is no doubt that tallity is important for team sports, especially for volleyball. The average length of the body in volleyball players is $9.4 \mathrm{~cm}$. This figure is predominant in non-sportsmen, the difference between these comparison groups is statistically significant. According to the sport position, it has been established that the hitters have significantly higher values of length, weight and area of the body surface than setters, libero and non-sports girls. The greatest values of all longitudinal sizes, we found in the group of hitters, between the setters and the libero, the difference is practically absent. Significant genetic conditionality of longitudinal body sizes gives reason to consider the differences identified as the result of sports selection. The specifics of sport activities in volleyball require adaptive changes on the part of the pelvic bones, which performs a peculiar function of the bone support for the internal organs during landing after the jumps. That is why, we consider that the increase in the size of the pelvis in volleyball players in comparison with non-sportsmen is a positive adaptation in this sport. Considering the bone system at the level of the whole organism, we can say that under the influence of regular physical loads of optimal level, all adaptation changes in it proceed as favorable, progressive and have the character of hypertrophy $[18,19,20]$. According to the radiological examination working hypertrophy of bones in young athletes is marked at $6-7$ months after the beginning of training, and at athletes of middle and senior age - in 1-1,5 years [21]. General adaptation changes occur in all bones of the skeleton, and local - in the most loaded in its parts. So, we found that all the circumferential dimensions of the body in the general group of volleyball players are significantly higher than that of girls who are not involved in sports. The most significant differences in body sizes can be the basis for creating a morphological picture of the volleyball players.

\section{CONCLUSIONS}

It was revealed that the volleyball players, in comparison with girls who are not involved in sport, have larger $(\mathrm{p}<0,001)$ total, longitudinal, circumferential body size, width of distal epiphysis, transverse diameter of the chest and pelvis. The setters prevail over the hitters and libero by the value of the most parameters. In hitters and setters most anthropo-somatometric parameters are larger $(\mathrm{p}<0.05-0.001)$, than in of girls.

Stroke volume and minute volume, a stroke index, volume speed of blood and the power of the left ventricle in volleyball players are significant, but the general peripheral 
resistance has a lower level in compare with girls, who were not involved in sports. There are no significant differences between the volleyball players of different roles in the level of the central hemodynamics parameters, except for the shock index, which in the libero is more prominent than the hitters ones.

\section{REFERENCES}

1. Myer G.D., Jayanthi N., Difiori J.P. et al. Does Early Sports Specialization Increase Negative Outcomes and Reduce the Opportunity for Success in Young Athletes? Sports Health. 2015;7(5): 37-442.

2. Barth M., Emrich E., Daumann F. Approaches and methods used for measuring organizational performance in national sport governing bodies from 1986 to 2014. A systematized review. Current Issues in Sport Science. 2018;3:1-22.

3. Stanković D., Pavlović R., Petković E. et al. The somatotypes and body composition of elite track and field athletes and swimmers. International Journal of Sports Science. 2018;8(3):67-77.

4. Bacciotti S., Baxter-Jones A., Gaya A. et al. Body physique and proportionality of Brazilian female artistic gymnasts. J. Sports Sci. 2018;36(7):749-756.

5. Sarafinyuk L.A., KhavturV.O., Fedoniuk L.Y. et al Evaluation of the Blood Venous Leave in Volleyball Players of the Mesomorphic Somatotype. Deutscher Wissenschaftsherold. 2019;3:40-42.

6. Tsukanova E.G., Korolkov A.N., Germanov G.N.. The predictive value of peripheral hemodynamic parameters in rheographic studies of muscular activity in athletes specializing in running for 800 meters. Scientific notes of the PF Lesgaft University. 2013;4(98):177-183.

7. Di Rienzo F., Hoyek N., Collet C., Guillot A. Physiological changes in response to apnea impact the timing of motor representations: a preliminary study. Behavioral and Brain Functions. 2014;10 (1):15.

8. Khapitska O.P., Ivanytsia A.O., Stefanenko I.S. et al Zmini reografichnih pokaznikiv gomilki u sportsmeniv riznih vidiv sportu [Changes in rheographic indicators of the shin at athletes of various sports]. Physiological journal. 2017;63(1):51-59 (UA).

9. Sarafinyuk L.A., Fomina L.V., Khavtur V.0. et al Features of total body sizes and anthropometric torso sizes in female volleyball players of mesomorphic somatotype. Bulletin of Morphology. 2018;3:32-36.

10. Sarafyniuk L.A., Pivtorak V.I., Khavtur V.O. et al. Peculiarities of the chest's size in female volleyball players of different constitutional types. Biomedical and Biosocial Anthropology. 2018;33:47-52.

11. Bykova E.A. Zavisimost rezultativnosti broskov v padenii ot urovnya situacionnoj trevozhnosti u gandbolistok razlichnyh amplua [The dependence of the impact of shots in the fall of the level of situational anxiety among handball players of various roles]. Physical education of students of creative specialties. 2006;1:13-19 (Ru).

12. Bairachnyi 0.V., Voronova V.I. Modelni osobistisni harakteristiki futbolistiv v zalezhnosti vid igrovogo amplua [Model personal characteristics of players depending on the role of the game]. The theory and methods of physical education and sport. 2008;1:90-94 UA).

13. Gotsentas A.A., Landyr A.P.Vzaimosvyaz morfologicheskih parametrovi funkcionalnyh pokazatelej organizma basketbolistok vysokoj kvalifikacii $s$ uchetom ih igrovogo amplua [The relationship of morphological parameters and functional parameters of the organism of highly qualified female basketball players, taking into account their playing roles]. Sports medicine. 2011;1(2)6:42-46 (Ru).

14. Bunak V.V. Antropometriya. Prakticheskij kurs [Anthropometry: a practical course]. M.: Uchpedgiz. 1941; 368 (Ru).
15. Martirosov E.G. Metodika issledovaniya sportivnoj antropologii [Research methodology of sports anthropology]. M.: Physical culture and sport. 1982; 200 (Ru).

16. Ronkin M.A., Ivanov L.B. Reografiya v klinicheskoj praktike [Rheography in clinical practice]. M.: Scientific medical firm MBN. 1997; 250 (Ru).

17. Vinogradova T.E. Instrumentalnye metody issledovaniya serdechnososudistoj sistemy [Instrumental methods for studying the cardiovascular system]. M.: Medicine. 1986; 416 (Ru).

18. Nikityuk B.A., Kogan B.I. Anatomo-antropologicheskie predposylki stanovleniya i rosta sportivnogo masterstva [Anatomical and anthropological background of the formation and growth of sportsmanship]. Vinnytsia: News of anthropology and anthropoecology. 1992;.118 (Ru).

19. Adhikari A., Nahida P., Islam R.N., et al. Importance of Anthropometric Characteristics in Athletic Performance from the Perspective of Bangladeshi National Level Athletes' Performance and Body Type. American Journal of Sports Science and Medicine. 2014; 2 (4):123-127.

20. Boiko V., Boychuk A., Nikitina I. et al. Basic clinical and pathogenetic aspects of developing the complications during multiple pregnancies. Wiadomości Lekarskie. 2019;72(1):52-55.

21. Smiianov V.A., Vygovskaya L.A. Intrauterine infections - challenges in the perinatal period (literature review). Wiad Lek. 2017;70(3):512-515.

The work is carried out within the framework of the initiative research work of the E. Pirogov Vinnitsa National Medical University (Vinnitsa, Ukraine) "0115U004045 Peculiriaties of hemodynamic parameters depending on the body structure in athletes of different sports".

\section{ORCID and contributionship:}

Larisa A. Sarafinjuk - 0000-0001-8253-5997 B,C

Olga P. Khapitska - 0000-0002-1333-5892 E,D

Larysa Ya. Fedoniuk - 0000-0003-4910-6888 ${ }^{E}$

Lyudmila V. Fomina - 0000-0002-1695-3442 ${ }^{\mathrm{F}}$

Daria A. Merkulova - 0000-0002-5021-2349 C

Yuriy V. Kyrychenko - 0000-0002-7945-8983 ${ }^{B, D}$

Petro V. Sarafinjuk - 0000-0002-6795-1279 ${ }^{\mathrm{A}}$

\section{Conflict of interest:}

The Authors declare no conflict of interest

\section{CORRESPONDING AUTHOR}

\section{Larysa Ya. Fedoniuk}

Medical Biology Department

I. Horbachevsky Ternopil National Medical University

Valova street, 9, Ternopil, 46000, Ukraine

tel: +380673999143

e-mail: Fedonyuk22Larisa@gmail.com

Received: 29.01.2020

Accepted: 01.04 .2020

A - Work concept and design, B - Data collection and analysis, C - Responsibility for statistical analysis,

D-Writing the article, $\mathbf{E}$-Critical review, $\mathbf{F}$ - Final approval of the article 